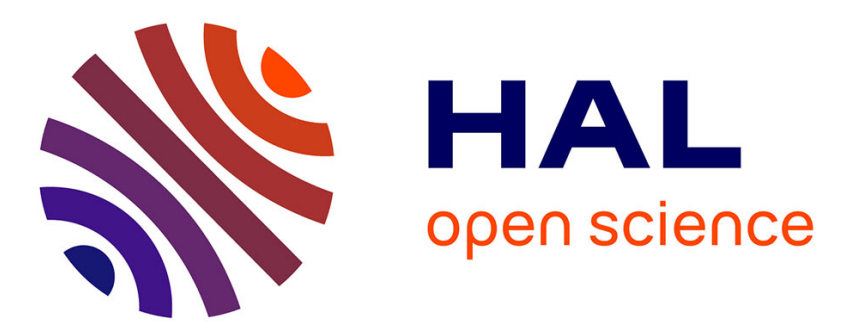

\title{
Five-Year Trends in Multifocal Electroretinogram for Patients With Birdshot Chorioretinopathy
}

Adriane Mailhac, Jose Labarere, Florent Aptel, Sylvie Berthemy, Laurence Bouillet, Christophe Chiquet

\section{To cite this version:}

Adriane Mailhac, Jose Labarere, Florent Aptel, Sylvie Berthemy, Laurence Bouillet, et al.. Five-Year Trends in Multifocal Electroretinogram for Patients With Birdshot Chorioretinopathy. American Journal of Ophthalmology, 2019, 200, pp.138-149. 10.1016/j.ajo.2018.11.022 hal-02272296

\section{HAL Id: hal-02272296 \\ https://hal.science/hal-02272296}

Submitted on 22 Oct 2021

HAL is a multi-disciplinary open access archive for the deposit and dissemination of scientific research documents, whether they are published or not. The documents may come from teaching and research institutions in France or abroad, or from public or private research centers.
L'archive ouverte pluridisciplinaire HAL, est destinée au dépôt et à la diffusion de documents scientifiques de niveau recherche, publiés ou non, émanant des établissements d'enseignement et de recherche français ou étrangers, des laboratoires publics ou privés.

\section{(ㅇ)(1) $\$$}

Distributed under a Creative Commons Attribution - NonCommerciall 4.0 International 


\section{Five-year trends in multifocal electroretinogram for patients with birdshot chorioretinopathy.}

Adriane MAILHAC, MD, ${ }^{1,2}$ José LABARERE,MD, PhD, ${ }^{1,4}$ Florent APTEL, MD, PhD, 1,2 Sylvie BERTHEMY-PELLET,MD, ${ }^{1}$ Laurence BOUILLET, MD, PhD, ${ }^{1,3}$ Christophe CHIQUET, MD, $\mathrm{PhD}^{1,2}$

1. Grenoble Alpes University, Grenoble, France

2. Department of Ophthalmology, Grenoble Alpes University Hospital, Grenoble, France

3. Department of Internal Medicine, Grenoble Alpes University Hospital, Grenoble, France

4. Quality of Care Unit, CIC 1406 INSERM, University Hospital, Grenoble, F-38043, France

Address for reprints / Corresponding author: Prof. Christophe CHIQUET, Department of Ophthalmology, Grenoble Alpes University Hospital, CS 10217, 38043 Grenoble cedex09, France, tel 33476765566, fax number: 33476765757 
Financial support: Association for Research and Teaching in Ophthalmology (ARFO, Grenoble, France). The sponsor of the funding organization had no role in the design or conduct of this research.

No conflicting relationship exists for any author.

Running head: mfERG follow-up in patients with birdshot chorioretinopathy. 


\section{INTRODUCTION}

Birdshot chorioretinopathy (BSCR) is a posterior autoimmune uveitis, usually symmetric, and strongly associated with human leukocyte antigen A 29. BSCR accounts for 0.5 to $1.5 \%$ of uveitis, with a higher prevalence in female and a mean age of symptom onset of 53 years. ${ }^{1}$ BSCR has an insidious progression and can cause a significant visual loss due to various complications, including macular edema, diffuse retinal atrophy, epiretinal membrane, and/or choroidal neovascularization.

Because visual acuity (VA) may remain stable despite steadily progressive deterioration of retinal function, ${ }^{2}$ it lacks sensitivity for detecting or monitoring patients with BSCR. Several functional and imaging technologies have been proposed for monitoring BSCR, ${ }^{3}$ including visual field, ${ }^{4}$ color vision, ${ }^{5}$ standard electroretinography (ERG), ${ }^{3,6-8}$ fluorescein (FA) and indocyanine green (ICGA) angiography, and optical coherence tomography (OCT). ${ }^{9,10}$ Yet these tests yield limited accuracy or reliability for assessing disease activity. This explains why monitoring BSCR patient remains challenging in routine practice.

Because electrophysiological testing may detect early functional changes, its use has been advocated for monitoring disease progression in uveitis. ${ }^{11}$ Three types of electroretinogramm are currently used in the clinical setting: full field, pattern, and multifocal ERGs. Multifocal ERG (mfERG) is a non-invasive method for objectively measuring retinal function within localized patches, especially the central retina, that is, up to $45^{\circ}$ of eccentricity around the central foveal area. Multifocal ERG waveform 
can be understood as a combination of overlapping ON- and OFF-bipolar cell contributions combined with smaller contributions from inner retina and photoreceptors. ${ }^{12}$ Many studies have reported on the diagnostic and prognostic values of full field ERG parameters for BSCR, including the light adapted $30-\mathrm{HZ}$ flicker response. ${ }^{6-8}$ In contrast, only two cross-sectional studies investigated the value of mfERG in BSCR. ${ }^{13,14}$ Birch et al. ${ }^{13}$ reported 1) lower mfERG responses for 6 eyes with macular atrophy compared to 8 eyes without macular thinning and 2) abnormal mfERG responses for patients with BSCR evolving for 10 years or more. Using a cross sectional study design, Chiquet et al. ${ }^{14}$ showed that amplitudes (AMP) and implicit times (IT) of the mfERG parameters were impaired in BSCR patients and were associated with other anatomical and functional test findings. In contrast to fullfield ERG, mfERG explores cone-driven light-adapted retinal function and provides objective assessment of central retinal function in different retinal areas within a short time frame. Furthermore, the multifocal technique may provide useful insights into the mechanisms of BSCR since the N1 wave represents the hyperpolarization of cones, and the P1 wave represents the depolarization of bipolar cells. Yet the value of mfERG for monitoring BSCR patients remains to be established and prospective longitudinal studies are warranted for this purpose.

This prospective cohort study of BSCR patients with a 5-year follow-up (FU) period aimed to investigate temporal trends in mfERG parameter values and elucidate their relationships with anatomical and functional tests. 


\section{METHODS}

\section{Study design}

As part of a prospective observational case series of BSCR, the present analysis focused on consecutive adult patients who were monitored at baseline, 3 and 5 years of FU, using mfERG in Grenoble Alpes University Hospital. This study complied with the declaration of Helsinki guidelines for research involving human subjects and was approved by the local Institutional Review board (IRB 00008855). All study participants provided written informed consent for conducting all ophthalmologic examinations.

\section{Patients}

All patients met the 2006 International consensus conference research criteria for diagnosis of $\mathrm{BSCR},{ }^{15}$ were older than 18 years, had no medical contraindications for performing FA and ICGA. They were recruited between January 2008 and December 2010.

\section{Data collection}

Baseline characteristics and FU data were prospectively collected, including measurement of VA (ETDRS chart), a 30-2 Swedish Interactive Threshold Algorithm (SITA) standard program on the Humphrey Field Analyzer (Carl Zeiss Meditec Inc., Dublin, CA) and a Lanthony desaturated panel D-15 test for color vision under standardized conditions of ambient illumination, with calculation of the total error score. ${ }^{16,17}$ All patients had a reliable visual field test, defined as a false positive error $<15 \%$, a false negative error $<15 \%$, and a fixation loss $<20 \%$. Quality of life (QoL) 
was assessed using the cross-cultural adaptation of the NEI Visual Function Questionnaire (VFQ-25) in French. ${ }^{18}$

Anatomical testing was based on FA, ICGA (Heidelberg, Germany) and optical coherence tomography (OCT) (Spectral domain Carl Zeiss Meditec Inc., or Spectral domain Heidelberg, Germany). Angiographic data were evaluated, in a blinded fashion by two independent investigators, ${ }^{19,20}$ and included optic disk hyperfluorescence, macular edema, retinal vascular staining and/or leakage (with an extension varying between 0 and 4 related quadrants), peripheral capillary leakage (extension: 0-4 quadrants), and posterior capillary leakage. Retinal vasculitis was defined as fluorescein staining of any retinal vessels proximal to the third bifurcation. $^{21}$ ICGA criteria were presence of hypocyanescence areas at the intermediate frame (10 min after the ICG injection). ${ }^{20}$

OCT data collected were central macular thickness (CMT), alteration of outer retina, and macular edema (ME). We defined ME in TD-OCT as CMT over $260 \mu \mathrm{m}$ and in SD-OCT as CMT over $295 \mu \mathrm{m} .{ }^{22,23}$ Other ME features included cystoid macular edema (CME), consisting of low-reflective intra-retinal spaces, clearly defined and separated by thin, high-reflective retinal tissue; diffuse ME consisting of increased macular thickness; small low-reflective areas with spongy appearance of the retinal layers. We defined alterations of the outer retina by the presence of a defects of at least one of four hyper-reflective outer retinal bands: the external limiting membrane (ELM); the ellipsoid portion of the inner segments (ellipsoid band); the cone outer segment/contact cylinder region (cone OS) and the RPE. ${ }^{24,25} \mathrm{CMT}$ was defined as the mean retinal thickness within the 1-mm central subfield. 
Each patient was followed using the same OCT machine. Patients initially included in 2008 had TD-OCT at baseline and were followed by TD-OCT over 5 years and SD-OCT from 2010. Cirrus measurement was defined as the reference measurement, and we used the conversion table to convert stratus (Cirrus = Stratus $\times 1+55.6)$ and Heidelberg measurements (Cirrus $=$ Spectralis $\times 0.8+36.4$ ) into cirrus $\mathrm{CMT}^{26}$

Severity of the disease and progression of inflammation were based on anatomical (fluorescein and ICG angiography, OCT) and functional (VA, visual field parameters) examinations.

Multifocal ERG (Vision Monitor; Métrovision, Pérenchies, France) was performed according to the International Society for Clinical Electrophysiology of Vision (ISCEV) protocol, ${ }^{27}$ using a 61 hexagon strategy and scaled hexagons. Stimulations were generated on a cathode ray tube monitor with a $120-\mathrm{Hz}$ frame rate. The luminance of white hexagons was $400 \mathrm{~cd} / \mathrm{m}^{2}$ and that of black hexagons 4 $\mathrm{cd} / \mathrm{m}^{2}$. The electrode used was the ERG-jet corneal electrode ${ }^{\mathrm{TM}}$. Dark frames were inserted after the white frames to achieve an $18-\mathrm{Hz}$ stimulus frequency. The surrounding luminance was set at $30 \mathrm{~cd} / \mathrm{m}^{2}$. The stimulus was calibrated following the ISCEV guidelines. ${ }^{27}$ After pupil dilation using phenylephrine 5\% (Europhta, Monaco) and tropicamide (Thea, Clermont-Ferrand, France), patient positioning, good fixation, best optical correction for near vision, and constant moderate room light for at least 15 minutes were ensured for each patient. Care was taken to eliminate any reflections from lens surfaces and to keep any bright light sources out of the patient's direct view. The first-order kernel mfERG responses were analyzed. Individual mfERG responses for the hexagons were grouped into five concentric 
rings centered on the fovea for analysis $(2,2-5,5-10,10-15$, and beyond 15 degrees of visual angle). Mathematically, the first order kernel is obtained by adding all the records that follow the presentation of a white hexagon (luminance, 400 $\mathrm{cd} / \mathrm{m}^{2}$ ) and subtracting all the records that follow a black hexagon. The following data were collected: the root mean square values (RMS), implicit time (IT) and AMP of $\mathrm{N} 1, \mathrm{P} 1$, and $\mathrm{N} 2$ waves. The N1 response was measured from the starting baseline to the base of the N1 trough; the $\mathrm{P} 1$ response AMP was measured from the N1 trough to the P1 peak. IT was measured from the onset of the stimulation to the trough or peak. Only averaged data including five rings were presented in the Results section.

Normative values (obtained from the manufacturer Métrovision) are (mean $\pm S D$ ): $-915 \pm 260 \mathrm{nV}$ for N1 AMP, $1633 \pm 395 \mathrm{NV}$ for P1 AMP, $23.2 \pm 1.3 \mathrm{msec}$ for N1

IT and $42.2 \pm 1.6 \mathrm{msec}$ for P1 IT. The reliability using the Metrovision device has been previously reported. in this study. ${ }^{28}$ For $\mathrm{N} 1$ and $\mathrm{P} 1$ waves, the percentage change for the intraindividual reproducibility study was $9.1 \%$ and $6.7 \%$, respectively, with the ERG-jet electrode and $18.2 \%$ and $13.5 \%$, respectively, using the same electrode. These published data have been used in the present study to categorize evolution of mfERG parameters into unchanged/ improved / deteriorated evolution from baseline.

\section{Statistical analysis}

Gender, treatments at baseline, evidence of photoreceptor alteration, ME and ERM on OCT, fluorescein and indocyanine green angiography findings were reported as numbers and percentages. Age, disease duration, VA, QoL score, foveal 
threshold, VF parameters, color vision score, CMT and ERG data (i.e. N1 and P1 implicit times and amplitudes) were summarized with means and standard deviation. Because of skewed distribution, disease duration and total error score were summarized with the median and 25th-75th percentiles.

Time trends in continuous mfERG parameters were modeled using linear regression for longitudinal data with time to FU visit entered as an independent variable. The linear time trend reflected the long-run tendency of mfERG parameter values to increase or decrease over time.

Temporal trends in continuous mfERG parameters were modelled using linear regression for longitudinal data with time to FU visit entered as an independent variable. To investigate univariate associations of mfERG parameters, we performed longitudinal regression modeling for continuous dependent variables, with characteristics and time to FU entered as independent covariates. We assessed the linearity assumption for continuous independent variables by using fractional polynomial functions. First-order interactions involving time to FU and each independent covariate were systematically tested for statistical significance. If a significant interaction was found, coefficient estimates were stratified by time to FU. To account for the hierarchical data structure, we used generalized estimated equations with the eye and FU observations nested within participants. ${ }^{28,29}$

Regression coefficient point estimates were reported along with $95 \%$ confidence intervals. Regression coefficients represent the variation in predicted mfERG parameter value for a one-unit increase in the covariate value. In longitudinal analysis, changes in mfERG parameter values were reported as "per year of FU". Two-sided p-values of $<0.05$ were considered statistically significant. All 
analyses were performed using Stata Special Edition version 14.0 (Stata Corporation, College Station, TX, USA).

\section{RESULTS}

Overall, 16 patients with a mean age of 60.2 (standard deviation, 7.8) were enrolled between 2008 and 2010 and underwent FU visits at 3.2 years (standard deviation 0.3 ) and 5.1 years (standard deviation, 0.2 ) of enrolment. Baseline characteristics are reported in Table 1. The mean time from diagnosis to enrolment was $4.8 \pm 4$ years. Eight eyes (25\%) had a cataract and none was pseudophakic at baseline while four eyes (12.5\%) underwent cataract surgery during the FU period.

No significant temporal trend was found for VA (increase of 0.46 letter per year of $\mathrm{FU}, 95 \%$ confidence interval $[\mathrm{Cl}],-0.51$ to $1.44, \mathrm{P}=.35$ ), color vision score (decrease of -9 per year of $\mathrm{FU}, 95 \% \mathrm{Cl},-20$ to $2, \mathrm{P}=.12$ ), foveal threshold (increase of $0.19 \mathrm{~dB}$ per year of $\mathrm{FU}, 95 \% \mathrm{Cl},-0.14$ to $0.52, \mathrm{P}=.26$ ) and mean deviation of visual field (increase of $0.07 \mathrm{~dB}$ per year of $\mathrm{FU}, 95 \% \mathrm{Cl},-0.19$ to $0.33, P=.60$ ), and quality of life score (increase of 0.71 per year of $\mathrm{FU}, 95 \% \mathrm{Cl},-0.89$ to $2.31, P=.39$ ) over the 5-year FU period.

The percentage of patients receiving corticosteroids alone or in combination with immunosuppressive treatment was $62 \%(10 / 16)$ and $56 \%(9 / 16)$ at baseline and 5 years of $\mathrm{FU}$, respectively $(P=.72)$. The percentage of patients with corticosteroids alone decreased over time (from $50 \%$ at baseline to $25 \%$ at the 5 -year FU) and the proportion of patients with corticosteroids and immunosuppressants increased (from $0 \%$ at baseline to $31 \%$ ). Over the 5 -year period, two out of 16 patients were newly 
treated, 3 out 16 did not change their treatment, 3 out 16 stopped their previous treatment and 4 out 16 had no treatment.

A significant decreasing temporal trend was observed over the 5-year FU period for $\mathrm{N} 1$ (37 nV, 95\% Cl, 24 to 51, p<.001), P1 (61 nV, 95\% Cl, 38 to 84, $\mathrm{p}<.001)$, and $\mathrm{N} 2(35 \mathrm{nV}, 95 \% \mathrm{Cl}, 11$ to $58, \mathrm{p}=.003$ ) amplitudes. Over the same period, $\mathrm{P} 1$ implicit time increased $(0.68 \mathrm{~ms}, 95 \% \mathrm{Cl}, 0.41$ to $0.94, \mathrm{p}<.001)$ while $\mathrm{N} 1$ (0.24 ms, $95 \% \mathrm{Cl},-0.04$ to $0.51, \mathrm{p}=.08)$ and $\mathrm{N} 2(0.89 \mathrm{~ms}, 95 \% \mathrm{Cl},-5.20$ to 6.98 , $p=.78$ ) implicit times did not vary significantly. Taken into account the intraindividual reproducibility of the mfERG, we reported that N1 AMP and P1 AMP deteriorated in 25/32 eyes (78\%) between baseline and FU3 (last visit, Supplementary material, Table 4).

Increasing N1 and P1 IT were both associated with increasing values of EDTRS score (in letters), foveal threshold, and quality of life and with increasing color vision score, mean deviation of visual field over the 5-year FU period (Table 2). A significant relationship was observed between decreasing P1 AMP values and increasing MD of visual field. Increased N2 AMP and longer N2 IT were associated with decreasing values of mean deviation of visual field over the 5-year FU period (Table 2) whereas longer N2 IT was also associated with increasing values of VA (EDTRS letters).

Over the 5-year FU period, longer N1 and P1 IT were both associated with macular edema (Table 3). Additionally P1 IT was also associated with optic disk hyperfluorescence and peripapillary hypocyanescence. Univariate associations were found between reduced N1 AMP values and the presence of venous vasculitis and peripheral capillary leakage. Reduced P1 AMP values were associated with the 
presence of photoreceptor layer alteration. No significant association was found between mfERG variables with posterior capillary leakage. Reduced N2 AMP and lower IT were significantly associated with photoreceptor alteration in OCT.

Figure 3 illustrates one case with a typical reduction of N1 and P1 AMP over time whereas visual field parameters and VA were stable, and no recurrence of vasculitis or CME occurred.

\section{DISCUSSION}

This prospective observational case series study showed that mfERG parameters worsen in BSCR patients during a 5-year FU period, with decreasing N1 and P1 AMP values and increasing P1 IT. Importantly, these temporal trends in mfERG parameter values were not paralleled by changes in classical functional parameters such as VA and visual field. However, substantial associations were found between N1 AMP and venous vasculitis and peripheral capillary leakage, whereas P1 AMP reflected alterations of the outer retina in OCT, after adjusting for time to FU. Waves amplitudes were well correlated to the visual field parameters whereas IT was well correlated to quality of life, VA and visual field parameters.

We confirmed that BSCR patients exhibit reduced AMP of P1 and N1 waves and increased IT of P1 over time. These data are consistent with our previous findings in a cross-sectional study, showing that BSCR eyes differed significantly from healthy eyes by a decrease in P1 (-17\%) and N2 AMP $(-27 \%)$ and an increase in $\mathrm{N} 1(9 \%)$ and $\mathrm{P} 1(5 \%) \mathrm{IT} .{ }^{14}$ In presence of macular atrophy in long-standing (> 10 years) BSCR patients, foveal mfERG amplitudes ${ }^{13}$ are reduced by 2.3 when compared to BSCR eyes without anatomic thinning. 
To our knowledge, the present study is the first to investigate trends in mfERG in patients with BSCR over a 5 year-period. The reduction in N1 and P1 AMP and increase in P1 IT suggest a worsening of retinal function across time whereas classical functional parameters such as VA, color vision and visual field parameters did not vary significantly. A previous study reporting standard ERG ${ }^{30}$ showed that $70 \%$ of the patients had a loss of inner and/or outer retinal functions over prolonged FU. Previous studies reporting the full-field cone system 30-Hz flicker ERG peak time ${ }^{6}$ the scotopic bright flash amplitudes (combined rods and cones), reduction in the a-wave and b-wave amplitudes, ${ }^{31,32}$ reduction in cone-b-wave implicit times and reduction in scotopic rod b-wave amplitudes ${ }^{7}$ illustrated that both the rod and cone systems are involved in BSCR.

Previous studies showed that VA did not reflect accurately disease severity, ${ }^{33}$ was stable ${ }^{2}$ or yielded a slow decline over time.$^{30}$ Color vision is impaired in BSCR, ${ }^{5,14}$ with $55-61 \%$ of patients abnormal color confusion scores. However the color vision score remained stable over 5 years in our study. There is more information in the literature concerning the abnormalities of the visual field, including peripheral constriction, generalized diminished sensitivity, enlarged blind spot, and central or paracentral scotoma. ${ }^{34,35}$ Recent studies showed that MD might be stable ${ }^{2}$ whereas PSD possibly reflecting sectorial changes increases, especially in patients who received short-term treatment. Pointwise linear regression analysis of luminance sensitivity can identify visual field loss despite a stable MD. ${ }^{35}$ These data highlight the need of complementary functional tests, which can reliably estimate the evolution of the retinal function. 
Our data show a positive correlation between mfERG and other functional tests despite the absence of temporal changes of VA, color vision, and visual field parameters over a 5-year period. Waves AMP were well correlated to the visual field sensitivity whereas ITs were well correlated to quality of life, VA and visual field parameters. An original finding of this study is the worsening of mfERG responses while VA and MD of visual field remains stable over time. There are several potential explanations for this discrepancy. First, changes in N1 and P1 AMP and/or IT may be early markers of worsening clinical outcomes that may not be captured over a 5year FU period. Second, we cannot exclude that this study was underpowered to detect any significant time trends in visual acuity, quality of life, visual field or color vision. A perspective of this work will consist to investigate the prognostic value of mfERG responses at baseline for the prediction of visual function in the long-term.

BSCR has a high impact on vision-related quality of life, especially for general health and near vision, difficulties with activities and depression, ${ }^{14}$ with a mean global VFQ-25 score around 70 consistent with previous study. ${ }^{36}$ In this study taking into account both eyes of each patient, we showed for the first time that (1) the reduced QoL score was not modified significantly during a 5-year period and (2) QoL score was significantly associated with $\mathrm{N} 1$ and P1 IT. This finding is interesting since previous report showed only a weak correlation between composite scores and VA. ${ }^{36}$

$\mathrm{P} 1$ wave abnormalities suggest a lesion at the cone receptor site and $\mathrm{ON}$ bipolar cells, with a delayed response from both neurons. ${ }^{37}$ The P1 IT is also known to be a very sensitive measure of outer retinal function. ${ }^{37}$ In BSCR patients, the outer retina damages, such as photoreceptor layer alteration and presence of macular 
edema were respectively correlated with decreased AMP and longer IT of P1. This finding confirms the pilot study of Birch who showed that BSCR patients with OCT macular thinning exhibit a significantly altered mfERG. ${ }^{13}$ These data highlights the importance of analyzing the outer retina. Loss of OFF-bipolar cells is known to decrease the amplitude of $\mathrm{N} 1 .^{37}$ We found that venous vasculitis and capillary leakage were specifically associated with a reduction in N1 AMP, probably by a deleterious effect on the inner retina, especially on bipolar cells. The origin of N2 wave remains uncertain. ${ }^{12} \mathrm{~A}$ recent study indicated that the activity of retinal ganglion cells contributed to the amplitude of the $\mathrm{N} 2$ of the mfERG. ${ }^{39}$ The univariate analysis done in our study shows that N2 AMP was associated with photoreceptor alterations but it was not possible to identify confounding factors and contributions of other retinal layers, such as the retinal ganglion cell layer. Contribution of N2 for the FU of uveitis patients should be confirmed by further studies, while association with VF and VA were found in this study.

The implicit times of the $\mathrm{N} 1$ and $\mathrm{P} 1$ response are also known to be a very sensitive measure of outer retinal function, ${ }^{37}$ and were correlated to the presence of macular edema. This finding is consistent with the correlation between CMT or macular edema and longer IT found previously in BSCR ${ }^{14}$ and diabetic patients. ${ }^{38,39}$

We did not find any correlations between mfERG parameters and ICGA data, such as the number of quadrants with hypocyanescent dots at the intermediate phase. This finding could be due to the relative independence between choroidal and retinal involvement. ${ }^{40,41} \mathrm{P} 1 \mathrm{IT}$ was correlated with peripapillary hypocyanescence, which is a frequent finding in BSCR. ${ }^{42,43}$ Future studies are needed to correlate choroidal thinning with changes of mfERG. ${ }^{44}$ 
The limitations of our study deserve mention. First, our study might be underpowered in detecting clinically significant temporal trends, due to the relatively limited sample size. Second, we investigated univariate associations only. Indeed, too few observations were available relative to the number of predictors included in multivariate analysis of mfERG. Hence, the multivariable model would fit the data set too closely and be likely to perform less well in new patients - a statistical phenomenon called overfitting. Furthermore the limited series of patients did not allow statistical comparisons for each ring separately. Third, five patients of the cohort were followed using TD-OCT since they were examined at baseline using TDOCT in 2008. For this reason, analysis of the outer retina was done according the IS/OS disruption and not systematically considering the four bands well described in SD-OCT (ELM, EZ, CIZ, RPE). We used a published formula in order to reduce the effect of using different OCT machines. We estimate that the range of error is slight and that CME detection was not affected by these calculations. Fourth, four eyes $(12.5 \%)$ were operated on for cataract during the study and the surgery was done between baseline and the first visit. The change in lens status may have changed the mfERG parameters. Cataract may reduce $\mathrm{N} 1$ and $\mathrm{P} 1$ amplitudes ${ }^{45}$ and cataract surgery may increase mfERG responses. ${ }^{46}$ Finally, mfERG is limited to the central 30 degrees, much less than standard ERG. Our previous study ${ }^{14}$ showed that the degree of eccentricity (five rings) modulated the values for RMS, P1 and N2 amplitude, and P1 implicit time. These differences were found essentially between ring $1+2$ and the other rings, suggesting that the macula is more sensitive to inflammation than the extrafoveal retina. This topographic information was not used statistically in the present study due to statistical limitations. We can therefore 
hypothetize that full field RDG and mfERG are complementary. One should note that these exams are time consuming and necessitates cooperation of the patient.

In conclusion, this longitudinal study of BSCR patients provides for the first time the evidence of worsening of mfERG responses in patients who were stable for other standard visual tests. MfERG, which is considered a reliable and accurate functional test, ${ }^{47}$ was able to detect variations in N1 and P1 AMP and P1 IT over the 5-year FU period. Longer N1 and P1 IT at each visit were associated with functional worsening and macular edema. On the other hand, waves AMP were associated with presence of venous vasculitis and peripheral capillary leakage for $\mathrm{N} 1$ and photoreceptor layer alteration for P1. Although our findings deserve replication, our study supports the use of mfERG for initial assessment and subsequent monitoring of BSCR activity. 


\section{REFERENCES}

1. Shah KH, Levinson RD, Yu F, Goldhardt R, Gordon LK, Gonzales CR, et al. Birdshot chorioretinopathy. Surv Ophthalmol. 2005 Dec;50(6):519-41.

2. Tomkins-Netzer O, Taylor SRJ, Lightman S. Long-term clinical and anatomic outcome of birdshot chorioretinopathy. JAMA Ophthalmol. 2014 Jan;132(1):57-62.

3. Comander J, Loewenstein J, Sobrin L. Diagnostic testing and disease monitoring in birdshot chorioretinopathy. Semin Ophthalmol. 2011 Sep;26(4-5):32936.

4. Gordon LK, Monnet D, Holland GN, Brézin AP, Yu F, Levinson RD. Longitudinal cohort study of patients with birdshot chorioretinopathy. IV. Visual field results at baseline. Am J Ophthalmol. 2007 Dec;144(6):829-37.

5. Holland GN, Shah KH, Monnet D, Brezin AP, Yu F, Nusinowitz S, et al. Longitudinal cohort study of patients with birdshot chorioretinopathy II: color vision at baseline. Am J Ophthalmol. 2006 Dec;142(6):1013-8.

6. Holder GE. Electrophysiological characterisation and monitoring in the management of birdshot chorioretinopathy. British Journal of Ophthalmology. 2005 Jun 1;89(6):709-18.

7. Sobrin L, Lam BL, Liu M, Feuer WJ, Davis JL. Electroretinographic monitoring in birdshot chorioretinopathy. Am J Ophthalmol. $2005 \mathrm{Jul}$;140(1):52-64.

8. Zacks DN, Samson CM, Loewenstein J, Foster CS. Electroretinograms as an indicator of disease activity in birdshot retinochoroidopathy. Graefes Arch Clin Exp Ophthalmol. 2002 Aug;240(8):601-7.

9. Symes R, Young M, Forooghian F. Quantitative Assessment of Retinal Degeneration in Birdshot Chorioretinopathy Using Optical Coherence Tomography. Ophthalmic Surg Lasers Imaging Retina. 2015 Dec;46(10):1009-12.

10. Teussink MM, Huis In Het Veld PI, de Vries LAM, Hoyng CB, Klevering BJ, 
Theelen T. Multimodal imaging of the disease progression of birdshot chorioretinopathy. Acta Ophthalmol. 2016 Dec;94(8):815-23.

11. Gouliopoulos, Moschos Marilita M, Kalogeropoulos C. Electrophysiological examination in uveitis: a review of the literature. Clinical Ophthalmology. 2014 Jan;199.

12. Hood DC, Frishman LJ, Saszik S, Viswanathan S. Retinal origins of the primate multifocal ERG: implications for the human response. Invest Ophthalmol Vis Sci. 2002 May;43(5):1673-85.

13. Birch DG, Williams PD, Callanan D, Wang R, Locke KG, Hood DC. Macular atrophy in birdshot retinochoroidopathy: an optical coherence tomography and multifocal electroretinography analysis. Retina (Philadelphia, Pa). 2010 Jun;30(6):930-7.

14. Chiquet C, Berthemy-Pellet S, Altayrac-Bethenod J, Aptel F, Labarere J, Quesada J-L, et al. MULTIFOCAL ELECTRORETINOGRAM IN BIRDSHOT CHORIORETINOPATHY: Retina. 2015 Jun;35(6):1256-65.

15. Levinson RD, Brezin A, Rothova A, Accorinti M, Holland GN. Research Criteria for the Diagnosis of Birdshot Chorioretinopathy: Results of an International Consensus Conference. American Journal of Ophthalmology. 2006 Jan;141(1):1857.

16. Lanthony P. [Evaluation of the desaturated Panel D-15. I. Method of quantification and normal scores]. J Fr Ophtalmol. 1986;9(12):843-7.

17. Török. Farnsworth-munsell FM 100-Hue, Farnsworth D-15 and lanthony D-15WEB-based scoring. 2006. Available at: http://www.torok.info/colorvision5/d15.htm.

18. Mangione CM, Lee PP, Gutierrez PR, Spritzer K, Berry S, Hays RD, et al. Development of the 25-item National Eye Institute Visual Function Questionnaire. Arch Ophthalmol. $2001 \mathrm{Jul} ; 119(7): 1050-8$.

19. Priem HA, Oosterhuis JA. Birdshot chorioretinopathy: clinical characteristics and evolution. Br J Ophthalmol. 1988 Sep;72(9):646-59. 
20. Fardeau C, Herbort CP, Kullmann N, Quentel G, LeHoang P. Indocyanine green angiography in birdshot chorioretinopathy. Ophthalmology. 1999 Oct;106(10):1928-34.

21. Monnet D, Brézin AP, Holland GN, Yu F, Mahr A, Gordon LK, et al. Longitudinal cohort study of patients with birdshot chorioretinopathy. I. Baseline clinical characteristics. Am J Ophthalmol. 2006 Jan;141(1):135-42.

22. Fiore $\mathrm{T}$, Androudi S, laccheri B, Lupidi M, Fabrizio G, Fruttini D, et al. Repeatability and Reproducibility of Retinal Thickness Measurements in Diabetic Patients with Spectral Domain Optical Coherence Tomography. Current Eye Research. 2013 Jun;38(6):674-9.

23. Browning DJ, Glassman AR, Aiello LP, Bressler NM, Bressler SB, Danis RP, et al. Optical Coherence Tomography Measurements and Analysis Methods in Optical Coherence Tomography Studies of Diabetic Macular Edema. Ophthalmology. 2008 Aug;115(8):1366-71.e1.

24. Spaide RF, Curcio CA. ANATOMICAL CORRELATES TO THE BANDS SEEN IN THE OUTER RETINA BY OPTICAL COHERENCE TOMOGRAPHY: Literature Review and Model. Retina. 2011 Sep;31(8):1609-19.

25. Nazari H, Dustin L, Heussen FM, Sadda S, Rao NA. Morphometric spectraldomain optical coherence tomography features of epiretinal membrane correlate with visual acuity in patients with uveitis. Am J Ophthalmol. $2012 \mathrm{Jul} ; 154(1): 78-86 . e 1$.

26. Roh Y-R, Park KH, Woo SJ. Foveal Thickness between Stratus and Spectralis Optical Coherence Tomography in Retinal Diseases. Korean Journal of Ophthalmology. 2013;27(4):268.

27. Hood DC, Bach M, Brigell M, Keating D, Kondo M, Lyons JS, et al. ISCEV standard for clinical multifocal electroretinography (mfERG) (2011 edition). Doc Ophthalmol. 2012 Feb;124(1):1-13.

28. Thimonier C, Daubas P, Bourdon L, Deral-Stephant V, Menu J-P, Vignal R, et al. [Multifocal ERG using ERG-jet and Gold Foil electrodes in normal subjects: comparison and reproducibility]. J Fr Ophtalmol. 2008 Jun;31(6 Pt 1):585-90. 
29. Glynn RJ, Rosner B. Regression methods when the eye is the unit of analysis. Ophthalmic Epidemiol. 2012 Jun;19(3):159-65.

30. Murdoch IE, Morris SS, Cousens SN. People and eyes: statistical approaches in ophthalmology. Br J Ophthalmol. 1998 Aug;82(8):971-3.

31. Oh KT, Christmas NJ, Folk JC. Birdshot retinochoroiditis: long term follow-up of a chronically progressive disease. Am J Ophthalmol. 2002 May;133(5):622-9.

32. Hirose $T$, Katsumi $O$, Pruett RC, Sakaue $H$, Mehta M. Retinal function in birdshot retinochoroidopathy. Acta Ophthalmol (Copenh). 1991 Jun;69(3):327-37.

33. Priem HA, De Rouck A, De Laey JJ, Bird AC. Electrophysiologic studies in birdshot chorioretinopathy. Am J Ophthalmol. 1988 Oct 15;106(4):430-6.

34. Touhami S, Fardeau C, Vanier A, Knoeri J, Simon C, Tezenas du Montcel S, et al. Visual Acuity in Birdshot Retinochoroidopathy Evaluation. Am J Ophthalmol. 2015 Oct;160(4):817-21.e2.

35. Shah KH, Levinson RD, Yu F, Goldhardt R, Gordon LK, Gonzales CR, et al. Birdshot chorioretinopathy. Surv Ophthalmol. 2005 Dec;50(6):519-41.

36. Arya B, Westcott M, Robson AG, Holder GE, Pavesio C. Pointwise linear regression analysis of serial Humphrey visual fields and a correlation with electroretinography in birdshot chorioretinopathy. $\mathrm{Br} J$ Ophthalmol. 2015 Jul;99(7):973-8.

37. Levinson RD, Monnet D, Yu F, Holland GN, Gutierrez P, Brezin AP. Longitudinal cohort study of patients with birdshot chorioretinopathy. V. Quality of life at baseline. Am J Ophthalmol. 2009 Feb;147(2):346-50.e2.

38. Hood DC. Assessing retinal function with the multifocal technique. Prog Retin Eye Res. 2000 Sep;19(5):607-46.

39. Kato F, Miura G, Shirato S, Sato E, Yamamoto S. Correlation between N2 amplitude of multifocal ERGs and retinal sensitivity and retinal nerve fiber layer thickness in glaucomatous eyes. Doc Ophthalmol. 2015 Dec;131(3):197-206. 
40. Fortune B, Schneck ME, Adams AJ. Multifocal electroretinogram delays reveal local retinal dysfunction in early diabetic retinopathy. Invest Ophthalmol Vis Sci. 1999 Oct;40(11):2638-51.

41. Leozappa M, Micelli Ferrari T, Grossi T, Pace V, Rinaldi ML, Battista D, et al. Prognostic prediction ability of postoperative multifocal ERG after vitrectomy for diabetic macular edema. Eur J Ophthalmol. 2008 Aug;18(4):609-13.

42. Herbort CP, Probst K, Cimino L, Tran VT. Differential inflammatory involvement in retina and choroïd in birdshot chorioretinopathy. Klin Monbl Augenheilkd. 2004 May;221(5):351-6.

43. Koizumi H, Pozzoni MC, Spaide RF. Fundus autofluorescence in birdshot chorioretinopathy. Ophthalmology. 2008 May;115(5):e15-20.

44. Piffer A-LL, Boissonnot $M$, Gobert F, Zenger A, Wolf $S$, Wolf $U$, et al. Relevance of wide-field autofluorescence imaging in Birdshot retinochoroidopathy: descriptive analysis of 76 eyes. Acta Ophthalmol. 2014 Sep;92(6):e463-9.

45. Young M, Fallah N, Forooghian F. Choroidal degeneration in birdshot chorioretinopathy. Retina (Philadelphia, Pa). 2015 Apr;35(4):798-802.

46. Birnbaum AD, Fawzi AA, Rademaker A, Goldstein DA. Correlation between clinical signs and optical coherence tomography with enhanced depth imaging findings in patients with birdshot chorioretinopathy. JAMA Ophthalmol. 2014 Aug;132(8):929-35.

47. Tam W-K, Chan H, Brown B, Yap M. Effects of different degrees of cataract on the multifocal electroretinogram. Eye (Lond). 2004 Jul;18(7):691-6.

48. Tam W-K, Chan H, Brown B, Leung K-W, Woo V, Yap M. Comparing the multifocal electroretinogram topography before and after cataract surgery. Curr Eye Res. $2005 \mathrm{Jul} ; 30(7): 593-9$.

49. Lai TYY, Chan W-M, Lai RYK, Ngai JWS, Li H, Lam DSC. The clinical applications of multifocal electroretinography: a systematic review. Surv Ophthalmol. 2007 Feb;52(1):61-96. 


\section{TABLES LEGENDS}

Table 1: Baseline patient and eye characteristics. Data are expressed as mean (standard deviation) or numbers (\%). CMT was defined as the mean retinal thickness within the 1-mm central subfield.

Table 2: Longitudinal analysis of univariate associations between mfERG variables and functional parameters

Regression coefficients represent the variation in predicted mfERG parameter value for a one-unit increase in the covariate value. $\beta$ regression coefficients represent change in multifocal electroretinogram parameters for a 1-unit variation in functional parameters. For instance, a one decibel increase in MD values (i.e. worsening of MD) is associated with a -0.4 ms variation in predicted N1 IT. In addition, a onedecibel decrease in MD values (i.e. improvement of MD) is associated with a $+23 \mathrm{nV}$ variation in predicted $\mathrm{N} 1 \mathrm{IT}$.

Abbreviations: $\mathrm{Cl}=$ confidence interval; $\mathrm{ms}=$ millisecond; deg= degree; $\mathrm{VA}=$ visual acuity

Table 3: Longitudinal analysis of univariate associations between mf ERG parameters and anatomical parameters 
Abbreviations: $\mathrm{Cl}=$ confidence interval; $\mathrm{ms}=$ millisecond; $\mathrm{OCT}=$ optical coherence tomography, $\mathrm{CMT}=$ central macular thickness, $\mathrm{PR}=$ photoreceptor, $\mathrm{CME}=$ cystoid macular edema, FA = fluorescein angiography, ICGA = indocyanin green angiography

- $\beta$ regression coefficients represent change in multifocal electroretinogram parameters for 1-unit variation in functional parameters.

Table 4 (supplementary material): Eye status according to intra-individual relative variation from baseline to the last follow-up (5-year FU) in N1 and P1 amplitude.

Intra-individual relative change was computed as (baseline value - FU3 value) / baseline value. For example, P1 AMP was defined as stable if the change between baseline visit and follow-up 3 (FU3) was comprised between $-6 ; 7 \%$ and $+6,7 \%$, improved (increased AMP) if increased by $6.7 \%$ or more, and deteriorated (decreased AMP) if decreased by $6.7 \%$ or more.

* Eye status at follow-up was determined using an intra-individual relative variation threshold of $9.1 \%$ for $\mathrm{N} 1$ amplitude and $6.7 \%$ for $\mathrm{P} 1$ amplitude, respectively. ${ }^{28}$ 


\section{FIGURES LEGENDS}

Figure 1: Trends in average values of mfERG parameter values at baseline (BL), follow-up 2 (FU2) at approximately 3 years and follow-up 3 (FU3) at approximately 5 years. The filled square is the average value of 16 patients and the vertical line is the standard deviation.

A: N1 amplitude (increase of $37 \mathrm{nV}$ per year of $\mathrm{FU}, 95 \% \mathrm{Cl}, 24$ to $51, P<.001$ )).

B: N1 implicit time (increase of $0.24 \mathrm{~ms}$ per year of $\mathrm{FU}, 95 \% \mathrm{Cl},-0.04$ to 0.51 , $P=.09$ ).

C: $\mathrm{P} 1$ amplitude (decrease in $61 \mathrm{nV}$ per year of $\mathrm{FU}, 95 \% \mathrm{Cl},-84$ to $-38, P<.001$ ).

D: P1 implicit time (increase of $0.68 \mathrm{~ms}$ per year of $\mathrm{FU}, 95 \% \mathrm{Cl}, 0.41$ to 0.94 , $P<.001)$.

Data are means and bars represent standard deviation.

FU: follow-up

Figure 2: Univariate associations between mf ERG parameters and anatomical and functional parameters

Figure 3: Time trend of mfERG parameters over a 5 year follow-up, with visual field and mfERG $\mathbf{N} 1$ and $P 1$ amplitude 3D representation. This female patient, 50 years old,diagnosed for Birdshot disease in 2008. Visual acuity was 20/30, had a venous vasculitis and a macular edema, and was initially treated by steroids and mycophenolate mofetil. In 2010, the patient was free of macular edema and vasculitis, under treatment with mycophenolate mofetil. Visual field was stable within the 5-year period with MD varying between $-1.94 \mathrm{~dB}$ and $-0.92 \mathrm{~dB}$. Foveal sensitivity and visual acuity were stable ( $37 \mathrm{~dB}$ and $20 / 20$, respectively). This case illustrates 
the worsening of mfERG parameters within the 5-year period: decrease in N1 amplitudes (from -865 nV to $-738 \mathrm{nV}$ ) and P1 amplitudes (from $1398 \mathrm{nV}$ to $1197 \mathrm{nV}$ ). Note that $\mathrm{N} 1$ amplitudes are illustrated in positive absolute values in the 3D graph. 
A

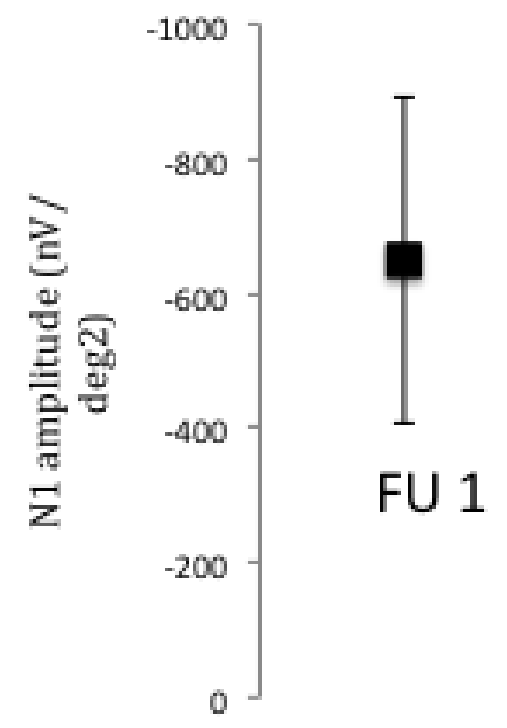

C

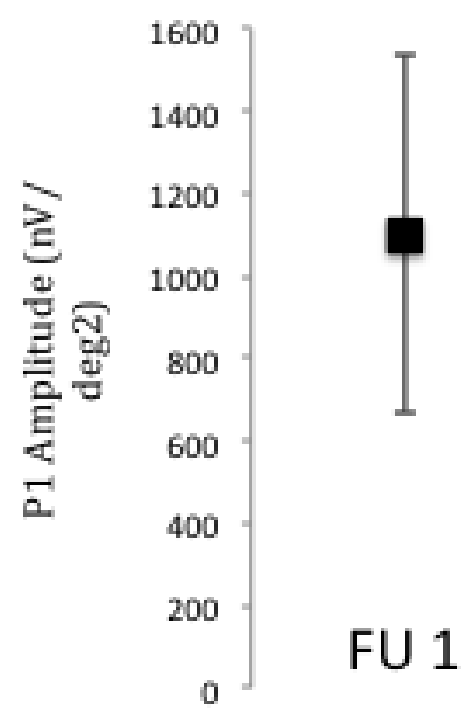

B

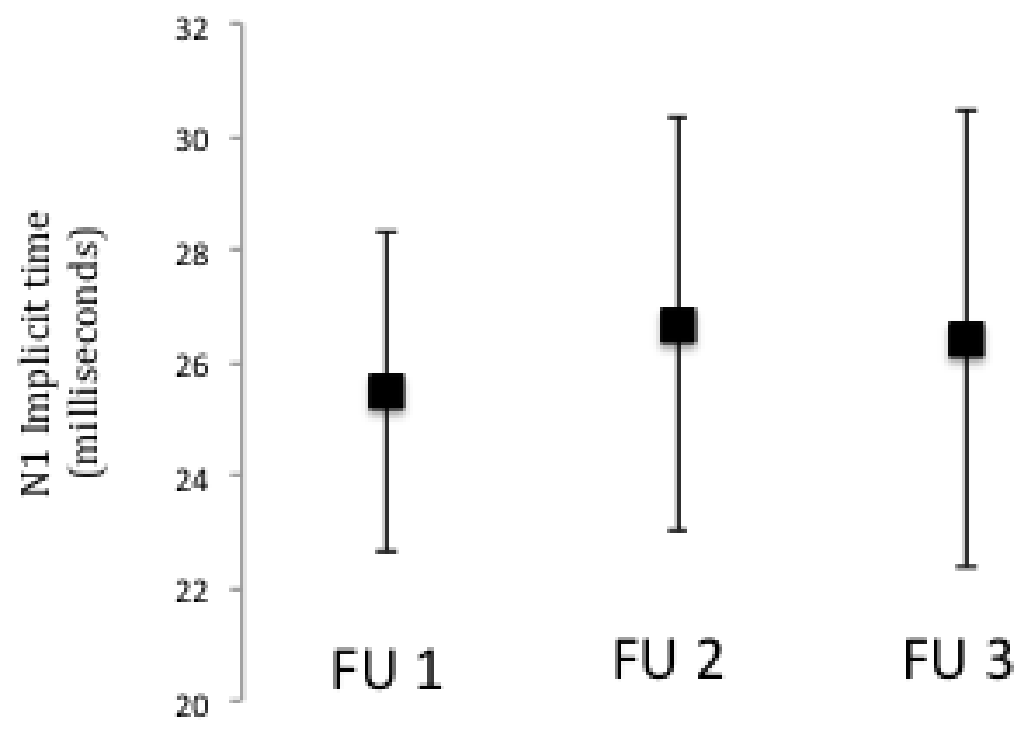

D

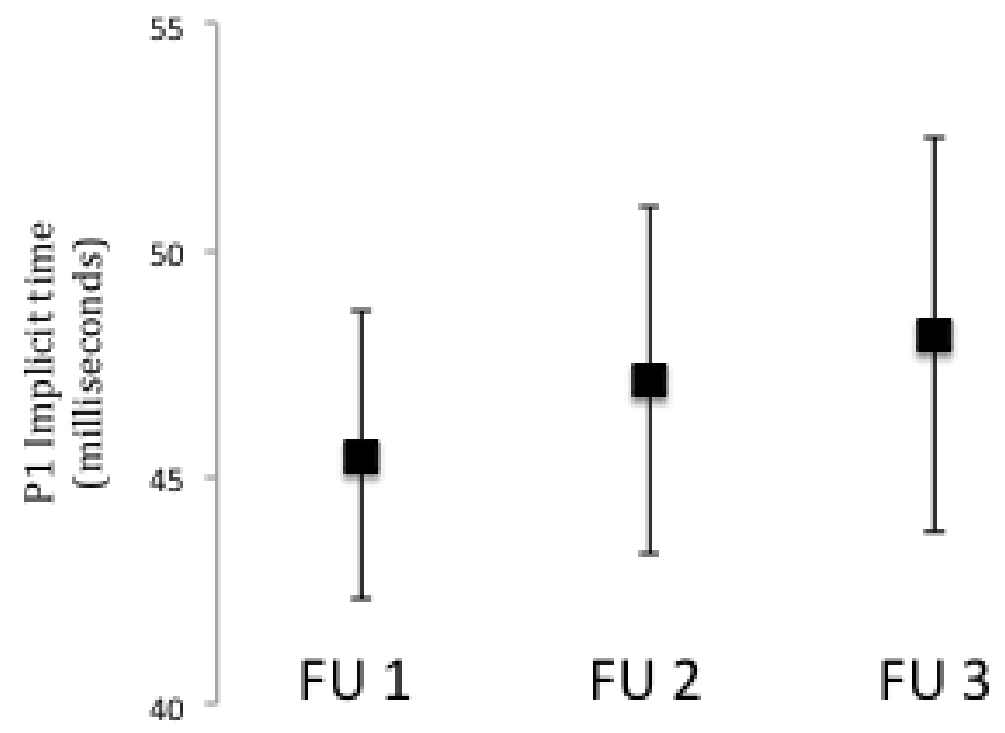




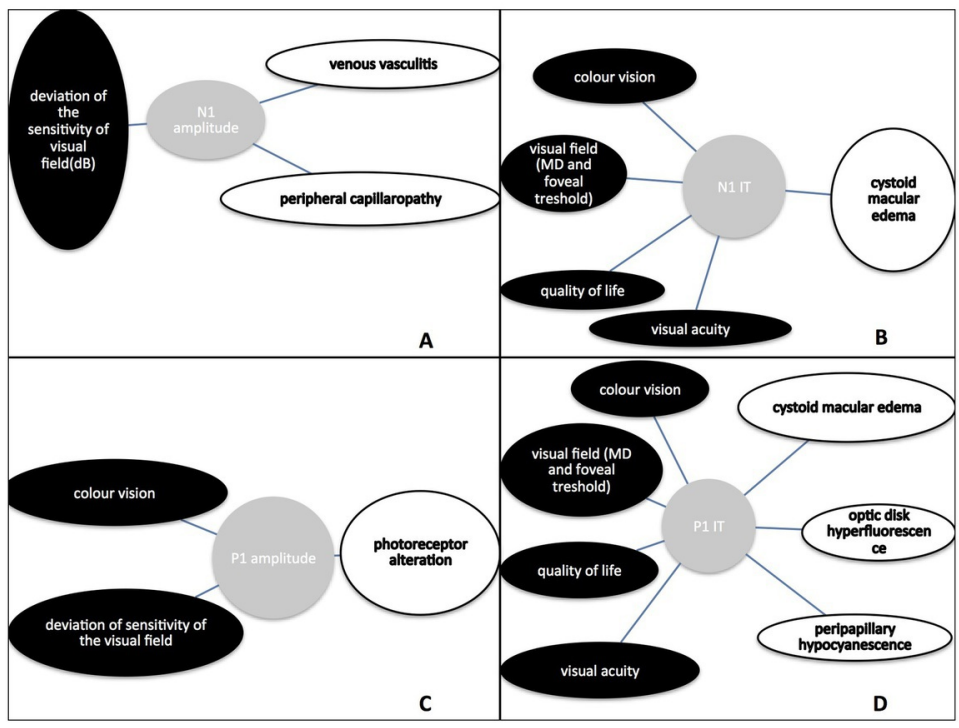



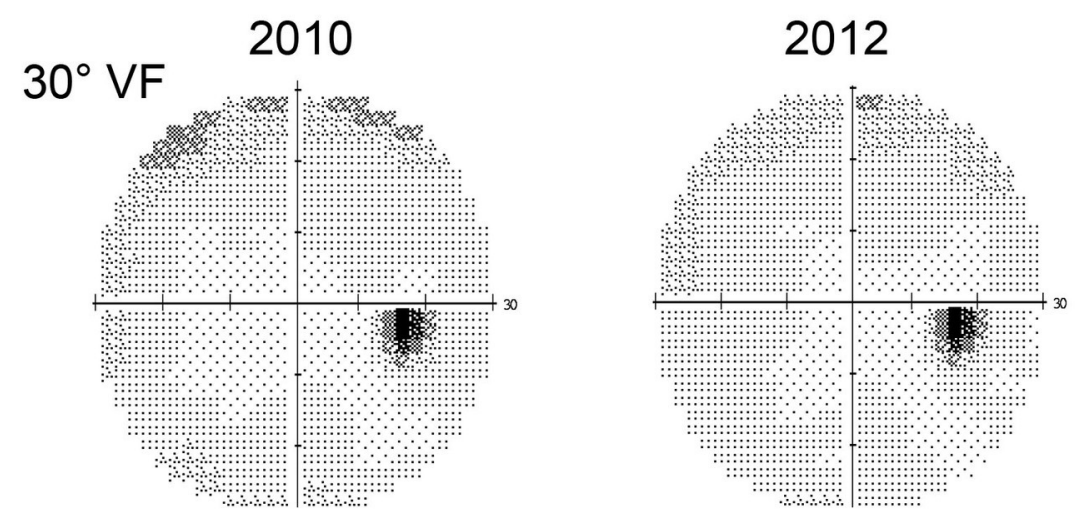

\section{N1 amplitude}
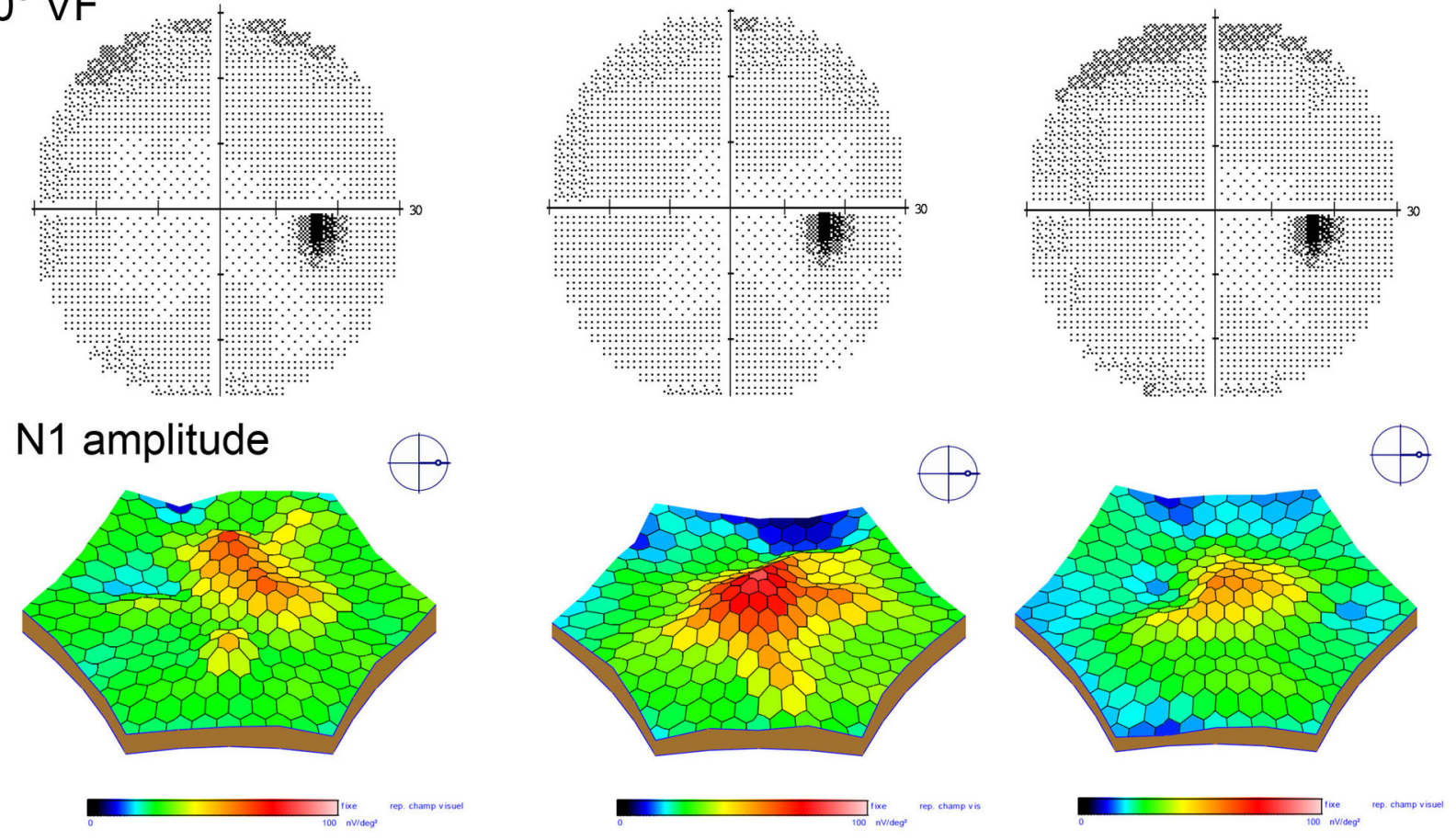

\section{P1 amplitude}
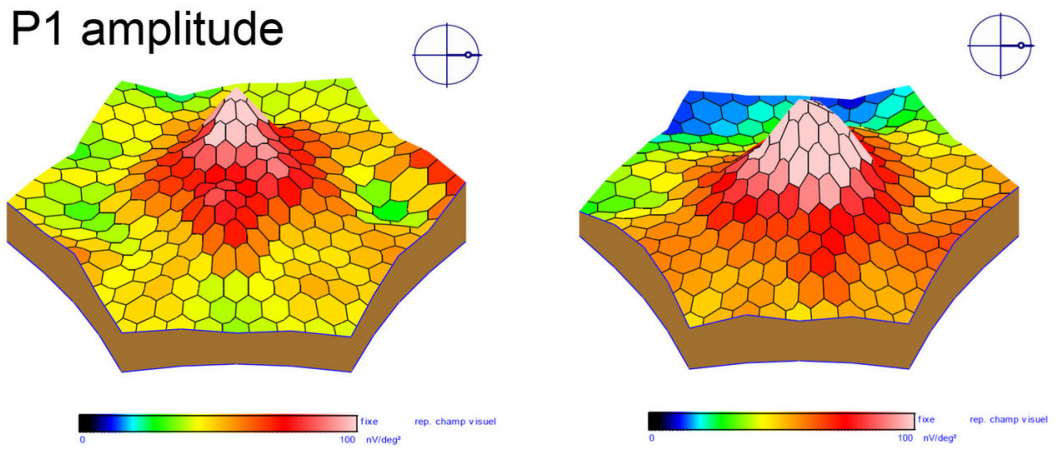

0

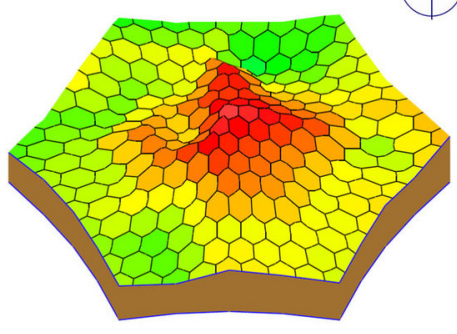


Table 1. Baseline characteristics.

BASELINE PATIENT CHARACTERISTICS $(n=16)$ *

\begin{tabular}{|c|c|c|c|}
\hline Male gender, $n(\%)$ & 6 & $(37.5)$ & \\
\hline Disease duration, median (IQR), $y$ & 4.2 & $(1.6-7.3)$ & \\
\hline Quality of life score, mean (SD) & 70.3 & $(15.2)$ & $: \quad E R G=$ \\
\hline \multicolumn{3}{|l|}{ Treatment, $n(\%)$} & \multirow{2}{*}{ electroretinog } \\
\hline None & 6 & $(37.5)$ & \\
\hline Corticosteroids & 8 & $(50.0)$ & \multirow{2}{*}{$\begin{array}{l}\text { raphy; IQR = } \\
\text { interquartile }\end{array}$} \\
\hline Immunosuppressive therapy & 2 & $(12.5)$ & \\
\hline \multicolumn{3}{|l|}{ BASELINE EYE CHARACTERISTICS $(n=32) \dagger$} & \multirow{2}{*}{$\begin{array}{r}\text { range } \begin{aligned} \text { i.e., } \\
25-75^{\text {th }}\end{aligned}\end{array}$} \\
\hline Visual acuity (ETDRS letters), mean (SD) & 76.6 & $(14.5)$ & \\
\hline \multicolumn{3}{|l|}{ Visual field } & \multirow{2}{*}{ percentiles); } \\
\hline Foveal threshold, mean (SD), $d B$ & 33.3 & $(4.5)$ & \\
\hline $\begin{array}{l}\text { Mean deviation of the sensitivity of visual field, } \\
\text { mean (SD), } d B\end{array}$ & -6.24 & $(6.04)$ & OCT $=$ optical \\
\hline \multicolumn{3}{|l|}{ Color vision } & coherence \\
\hline Total error score, median (IQR) & 140 & $(88-244)$ & tomography; \\
\hline \multicolumn{3}{|l|}{ OCT data } & \\
\hline Central macular thickness, mean (SD), $\mu \mathrm{m}$ & 260 & $(90)$ & \multirow{4}{*}{$\mathrm{SD}=$ standard } \\
\hline Photoreceptor alteration, $n(\%)$ & 5 & $(15.6)$ & \\
\hline Cystoid macular edema, $n(\%)$ & 4 & $(12.5)$ & \\
\hline Epiretinal membrane, $n(\%)$ & 12 & $(37.5)$ & \\
\hline \multicolumn{3}{|l|}{ ERG data } & \multirow[t]{2}{*}{ Normative } \\
\hline $\mathrm{N} 1$ amplitude, mean (SD), $n V$ & -648 & $(243)$ & \\
\hline N1 implicit time, mean (SD), $m s$ & 25.4 & $(2.8)$ & \multirow{2}{*}{$\begin{array}{r}\text { values } \\
\text { (obtained }\end{array}$} \\
\hline P1 amplitude, mean (SD), $n V$ & 1099 & $(432)$ & \\
\hline P1 implicit time, mean (SD), $m s$ & 45.4 & $(3.1)$ & \multirow{3}{*}{$\begin{array}{l}\text { from the } \\
\text { manufacturer }\end{array}$} \\
\hline $\mathrm{N} 2$ amplitude, mean (SD), $n V$ & -821 & $(380)$ & \\
\hline N2 implicit time, mean (SD), $m s$ & 65.3 & $(4.8)$ & \\
\hline \multicolumn{3}{|l|}{ Fluorescein angiography } & \multirow{2}{*}{ Métrovision) } \\
\hline Posterior capillary leakage, $n(\%)$ & 10 & $(31.2)$ & \\
\hline Optic disk hyperfluorescence, $n(\%)$ & 6 & $(18.8)$ & (mean \\
\hline $\begin{array}{l}\text { Venous vasculitis, } n(\%) \\
\quad \text { Absence }\end{array}$ & 19 & & $\pm S D): \quad-915$ \\
\hline $\begin{array}{l}\text { Absence } \\
1 \text { quadrant }\end{array}$ & 3 & $\begin{array}{r}(59.4) \\
(9.4)\end{array}$ & $\pm 260 \mathrm{nV}$ for \\
\hline 2 quadrants & 4 & $(12.5)$ & N1 AMP 1632 \\
\hline 3 quadrants & 4 & $(12.5)$ & \\
\hline 4 quadrants & 2 & $(6.2)$ & \pm 395 for $\mathrm{P} 1$ \\
\hline \multicolumn{3}{|l|}{ Peripheral capillary leakage, $n(\%)$} & \multirow{6}{*}{$\begin{array}{l}\text { AMP, } 23.2 \\
\pm 1.3 \text { ms for } \\
\text { N1 IT and } \\
42.2 \pm 1.6 \mathrm{~ms}\end{array}$} \\
\hline Absence & 20 & $(62.5)$ & \\
\hline 1 quadrant & 2 & $(6.2)$ & \\
\hline 2 quadrants & 1 & $(3.1)$ & \\
\hline 3 quadrants & 0 & $(0.0)$ & \\
\hline 4 quadrants & 9 & $(28.1)$ & \\
\hline \multicolumn{3}{|l|}{ Indocyanin green angiography } & \multirow[t]{2}{*}{ for P1 IT. } \\
\hline Peripapillary hypocyanescence, $n(\%)$ & 17 & $(53.1)$ & \\
\hline Dark dots, $n(\%)$ & & & \\
\hline Absence & 2 & $(6.2)$ & * Values were \\
\hline 1 quadrant & 3 & $(9.4)$ & Pence \\
\hline 2 quadrants & 3 & $(9.4)$ & missing \\
\hline 3 quadrants & 7 & (21.9) & quality of life \\
\hline 4 quadrants & 17 & (53.1) & \\
\hline
\end{tabular}


disease duration $(\mathrm{n}=1)$.

† $\mathrm{N} 2$ amplitude and N2 implicit times were missing at baseline for one eye in one patient. 
Table 2. Longitudinal analysis of univariable associations between mfERG and functional parameters.

\begin{tabular}{|c|c|c|c|c|c|c|c|c|c|c|c|c|}
\hline \multirow[b]{2}{*}{ Parameters } & \multicolumn{3}{|c|}{ N1 amplitude, $n V$} & \multicolumn{3}{|c|}{ N1 implicit time, $m s$} & \multicolumn{3}{|c|}{ P1 amplitude, $n V$} & \multicolumn{3}{|c|}{ P1 implicit time, $m s$} \\
\hline & $\beta^{*}$ & $(95 \% \mathrm{CI})$ & $P$ & $\beta^{*}$ & $(95 \% \mathrm{CI})$ & $P$ & $\beta^{*}$ & $(95 \% \mathrm{CI})$ & $P$ & $\beta^{*}$ & $(95 \% \mathrm{CI})$ & $P$ \\
\hline $\begin{array}{l}\text { Visual acuity } \\
\text { (ETDRS letters) }\end{array}$ & -2.24 & $(-4.91$ to 0.43$)$ & .10 & -0.09 & $(-0.13$ to -0.04$)$ & $<.001$ & 2.33 & $(-2.36$ to 7.02$)$ & .33 & -0.05 & $(-0.10$ to 0.00$)$ & .05 \\
\hline Quality of life & -1 & ( -4 to 2$)$ & .52 & -0.08 & $(-0.13$ to -0.02$)$ & .004 & 0.7 & $(-4.8$ to6.3) & .80 & -0.06 & $(-0.12$ to -0.02$)$ & .04 \\
\hline Visual field, $\mathrm{dB}$ & & & & & & & & & & & & \\
\hline Foveal threshold & 2.3 & $(-5.8$ to 10.4$)$ & .56 & -0.3 & $(-0.4$ to -0.1$)$ & $<.001$ & 4 & ( -11 to 18$)$ & .61 & -0.2 & $(-0.4$ to -0.1$)$ & .003 \\
\hline Mean deviation & -9.3 & $(-18.5$ to -0.1$)$ & .05 & -0.4 & $(-0.5$ to -0.3$)$ & $<.001$ & 23 & (8 to 38$)$ & .002 & -0.4 & $(-0.6$ to 0.3$)$ & $<.001$ \\
\hline Color vision & 0.20 & $(-0.03$ to 0.43$)$ & .10 & 0.01 & (0.007 to 0.01$)$ & $<.001$ & -0.5 & $(-0.9$ to -0.1$)$ & .01 & 0.008 & $(0.004$ to 0.010$)$ & $<.001$ \\
\hline
\end{tabular}


Table 2. (Continued)

\begin{tabular}{|c|c|c|c|c|c|c|}
\hline \multirow[b]{2}{*}{ Parameters } & \multicolumn{3}{|c|}{ N2 amplitude, $n V$} & \multicolumn{3}{|c|}{ N2 implicit time, $m s$} \\
\hline & $\beta^{*}$ & $(95 \% \mathrm{CI})$ & $P$ & $\beta^{*}$ & $(95 \% \mathrm{CI})$ & $P$ \\
\hline $\begin{array}{l}\text { Visual acuity } \\
\text { (ETDRS letters) }\end{array}$ & -2.45 & $(-7.07$ to 2.17$)$ & .30 & 1.18 & (0.86 to 1.49$)$ & $<.001$ \\
\hline Quality of life & -0.5 & $(-6.3$ to 5.4$)$ & .88 & -0.43 & $(-0.28$ to 1.13$)$ & .24 \\
\hline Visual field, dB & & & & & & \\
\hline Foveal threshold & -3.0 & $(-17.3$ to 11.3$)$ & .68 & 1.3 & $(-0.9$ to 3.4$)$ & .26 \\
\hline Mean deviation & -22.3 & $(-36.5$ to -8.2$)$ & .002 & 1.9 & (0.8 to 3.0 ) & .001 \\
\hline Color vision & 0.55 & (0.14 to 0.96$)$ & .009 & -0.02 & $(-0.08$ to 0.05$)$ & 0.59 \\
\hline
\end{tabular}

Abbreviations: $\mathrm{CI}=$ confidence interval; $\mathrm{ms}=$ millisecond; $\mathrm{deg}=$ degree

* $\beta$ regression coefficients represent change in multifocal electroretinogram parameters associated with a 1-unit variation in functional parameters. For instance, a 1-decibel decrease in mean deviation value from $-5 \mathrm{~dB}$ to $-6 \mathrm{~dB}$ (reflecting a worsening in mean deviation value) was associated with a $0.4 \mathrm{~ms}$ increase in $\mathrm{N} 1$ implicit time. A 1-decibel increase in mean deviation value from $-5 \mathrm{~dB}$ to $-4 \mathrm{~dB}$ (reflecting an improvement in mean deviation value) was associated with a $23 \mathrm{nV}$ increase in P1 amplitude. 
Table 3. Longitudinal analysis of univariate associations between multifocal electroretinogram parameters and anatomical parameters.
N1 amplitude, $n V$
N1 implicit time, $m s$
P1 amplitude, $n V$
P1 implicit time, $m s$

\begin{tabular}{|c|c|c|c|c|c|c|c|c|c|c|c|c|}
\hline Parameters & $\beta^{*}$ & (95\%CI) & $P$ & $\beta^{*}$ & $(95 \% \mathrm{CI})$ & $P$ & $\beta^{*}$ & (95\%CI) & $P$ & $\beta^{*}$ & (95\%CI) & $P$ \\
\hline \multicolumn{13}{|l|}{ OCT } \\
\hline $\mathrm{CMT}$ & 0.06 & $(-0.35$ to .49$)$ & .75 & 0.001 & $\begin{array}{l}(-0.006 \\
.01)\end{array}$ & .67 & 0.22 & $(-0.52$ to 0.96$)$ & .56 & 0.001 & $(-0.007$ to .01$)$ & .72 \\
\hline PR alteration & 2.37 & $(-70.51$ to 75.25$)$ & .95 & 0.90 & $\begin{array}{l}(-0.62 \\
2.43)\end{array}$ & .25 & -145.46 & $(-273.56$ to -17.36$)$ & .03 & 0.92 & $(-0.59$ to 2.44$)$ & .23 \\
\hline CME & -9.4 & $(-72.93$ to 54.1$)$ & .77 & 1.38 & (0.08 to 2.68$)$ & .04 & -75.63 & $(-186.48$ to 35.21$)$ & .18 & 1.48 & (0.21 to 2.75$)$ & .02 \\
\hline \multicolumn{13}{|l|}{$\begin{array}{l}\text { Fluorescein } \\
\text { angiography }\end{array}$} \\
\hline $\begin{array}{l}\text { Posterior capillary } \\
\text { leakage }\end{array}$ & -21.90 & $(-85.30$ to 41.49$)$ & .50 & -0.34 & $(-1.64$ to .95$)$ & .60 & 31.95 & $(-79.55$ to 143.46$)$ & .57 & -0.87 & $(-2.15$ to .39$)$ & .18 \\
\hline Venous vasculitis & -24.10 & $(-42.51$ to -5.70$)$ & .01 & 0.26 & $(-0.12$ to .65$)$ & .18 & 30.21 & $(-2.77$ to 63.20$)$ & .07 & -0.02 & $(-0.41$ to .36$)$ & .88 \\
\hline $\begin{array}{l}\text { Peripheral } \\
\text { capillary leakage }\end{array}$ & -21.35 & $(-39.07$ to -3.63$)$ & .02 & -0.24 & $(-0.61$ to .12$)$ & .19 & 59.82 & (30.31 to 89.33 ) & $<0.001$ & -0.35 & $(-0.72$ to .004$)$ & .05 \\
\hline $\begin{array}{l}\text { Optic disk } \\
\text { hyperfluorescence }\end{array}$ & 16.78 & $(-46.97$ to 80.54$)$ & .61 & 0.72 & $\begin{array}{l}(-0.60 \\
2.05)\end{array}$ & .28 & -75.73 & $(-186.94$ to 35.47$)$ & .18 & 1.62 & (0.36 to 2.89 ) & .01 \\
\hline \multicolumn{13}{|l|}{$\begin{array}{l}\text { Indocyanine green } \\
\text { angiography }\end{array}$} \\
\hline Dark dots areas & -14.46 & $(-39.19$ to 10.25$)$ & .25 & 0.00 & $(-0.50$ to .52$)$ & .98 & 17.89 & $(-25.80$ to 61.59$)$ & .42 & -0.17 & $(-0.68$ to .33$)$ & .50 \\
\hline $\begin{array}{l}\text { Peripapillary } \\
\text { hypocyanescence }\end{array}$ & 79.48 & $(-3.54$ to 162.50$)$ & .06 & 0.50 & $\begin{array}{l}-(1.13 \\
2.14)\end{array}$ & .55 & -16.39 & $\begin{array}{r}(-163.47 \text { to } \\
130.68)\end{array}$ & .83 & 2.23 & (0.64 to 3.83$)$ & .006 \\
\hline
\end{tabular}


Table 3. (Continued)

\begin{tabular}{|c|c|c|c|c|c|c|}
\hline \multirow[b]{2}{*}{ Parameters } & \multicolumn{3}{|c|}{ N2 amplitude, $n V$} & \multicolumn{3}{|c|}{ N2 implicit time, $m s$} \\
\hline & $\beta^{*}$ & $(95 \% \mathrm{CI})$ & $P$ & $\beta^{*}$ & $(95 \% \mathrm{CI})$ & $P$ \\
\hline \multicolumn{7}{|l|}{ OCT } \\
\hline CMT & -0.32 & $(-1.05$ to .42$)$ & .40 & 0.08 & $(-0.04$ to .21$)$ & .19 \\
\hline PR alteration & 182.9 & (57.5 to 308.4 ) & .004 & -21.9 & $(-42.6$ to -1.1$)$ & .04 \\
\hline CME & 104.9 & $(-10.9$ to 220.6$)$ & .07 & 7.1 & $(-18.7$ to 32.9$)$ & .59 \\
\hline \multicolumn{7}{|l|}{ Fluorescein angiography } \\
\hline Posterior capillary leakage & 38.9 & $(-74.3$ to 152.2$)$ & .50 & 13.1 & $(-6.7$ to 32.8$)$ & .19 \\
\hline Venous vasculitis & -2.1 & $(-38.4$ to 34.2$)$ & .91 & 2.3 & $(-4.5$ to 9.0$)$ & .51 \\
\hline Peripheral capillary leakage & -32.5 & $(-64.9$ to -0.1$)$ & .05 & 3.6 & $(-1.9$ to 9.0$)$ & .21 \\
\hline Optic disk hyperfluorescence & 81.5 & $(-35.4$ to 198.5$)$ & .17 & 2.6 & $(-23.0$ to 28.1$)$ & .84 \\
\hline \multicolumn{7}{|l|}{ Indocyanin green angiography } \\
\hline Dark dots areas & 10.7 & $(-33.9$ to 55.2$)$ & .64 & -2.4 & $(-10.7$ to 5.9$)$ & .57 \\
\hline Peripapillary hypocyanescence & 3.5 & $(-144.9$ to 152.0$)$ & .96 & -7.9 & $(-27.4$ to 11.7$)$ & .43 \\
\hline
\end{tabular}

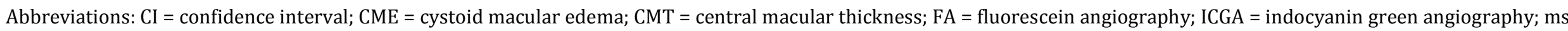
= millisecond OCT $=$ optical coherence tomography; $\mathrm{PR}=$ photoreceptor .

* $\beta$ regression coefficients represent change in multifocal electroretinogram parameters for a 1-unit variation in functional parameters 
Table 4. Eye status according to intra-individual relative variation from baseline to the last follow-up (5-year FU) in N1 and P1 amplitude.

\begin{tabular}{lrrr} 
& & \multicolumn{2}{c}{ Intra-individual relative variation, \% } \\
\cline { 3 - 4 } Status at follow-up* & No. eyes & Median & (range) \\
\hline N1 amplitude & 5 & -2.9 & $(-6.8$ to 3.0$)$ \\
Unchanged & 2 & -27.3 & $(-40.6$ to -14.0$)$ \\
Improved & 25 & 32.1 & $(12.0$ to 66.8$)$ \\
Deteriorated & & & \\
P1 amplitude & 7 & 2.9 & $(-2.0$ to 5.2$)$ \\
Unchanged & 0 & $\ldots$ & $(\ldots)$ \\
Improved & 25 & 23.9 & $(7.0$ to 66.4$)$ \\
Deteriorated & & & \\
\hline
\end{tabular}

